\title{
OTROS CARIBES: DE LAS ANTILLAS AL CONTINENTE (SUDAMÉRICA, CENTROAMÉRICA Y NORTEAMÉRICA)
}

\author{
POR \\ Graciela Maglia \\ Pontificia Universidad Javeriana, Bogotá \\ Instituto Caro y Cuervo
}

El presente volumen se propone avanzar un tramo en el conocimiento de las configuraciones culturales y expresiones artísticas otras del Caribe en su histórica e irreductible heterogeneidad, con énfasis en problemáticas que invitan a renovadas formas de pensar esta frontera cruzada, donde las alteridades persisten más allá de toda codificación. Las identidades afrodiaspóricas, el Caribe continental de las Américas y sus intersecciones menos exploradas, las Antillas anglófonas y francófonas, la oralitura afrocriolla, las inclusiones, encrucijadas y límites de los Estudios Caribeños serán algunos de los debates aquí planteados.

Frente a las tendencias homogenizadoras y normalizadoras de la sociedad de consumo, los escritores caribeños proponen proteger su diversidad, lejos de los fundamentalismos nacionalistas, las identidades cerradas y los imperativos territorialistas intentando, como lo señala Patrick Chamoiseau en consonancia con la reflexión de Edouard Glissant, una puesta en relación en la que "no se integra, [sino que] se acepta al otro en su opacidad", postulando una identidad plural, relacional, un "imaginario de la complejidad", una unidad en la diversidad así como una transformación de los territorios en lugares solidarios, no solitarios. En este orden de ideas, como nativo de las Indias Occidentales y a la vez habitante de América, Derek Walcott plantea la posibilidad de una identidad compleja, que discurre en "una ambigüedad sin crisis", a la vez antillana y americana. Por otra parte, en una recuperación no conciliadora del pasado europeo, rescata la imitación como motor de la cultura caribeña, que si bien se gestó a imagen y semejanza del Viejo Mundo, resultó en la creación de un heterocosmos, gracias a la energía creolizadora de la imaginación como respuesta defensiva.

Por su parte, y retomando el tema desde el debate en torno al Manifiesto Antropófago de Oswaldo Andrade y su atribuido valor anticipador de conceptos claves de la teoría latinoamericana del consumo cultural, como transculturación, traducción cultural, calibanismo, entre otros, Carlos Jáuregui rescata la antropofagia otra de Oswaldo Costa, representante del contra-culturalismo colonialista del modernismo brasileño, articulada 
en torno de la crítica a la situación colonial y el occidentalismo. "Antropofagia [la de Costa] desafiaría entonces la idea de América y del Brasil como copias defectuosas de Europa reformulando de manera afirmativa la imitatio como deglutição". En esta línea de apertura, en un texto casi testimonial, el sociólogo británico de origen guyanés Paul Gilroy plantea el tránsito del Black Atlantic - espacio transnacional que conecta la diáspora africana con la modernidad-a la melancolía poscolonial. Esta nueva perspectiva reposiciona las relaciones coloniales en la actualidad desde el trabajo de la memoria del imperio y la concepción de una multiculturalidad posible.

En tanto espacios expuestos a continuos emplazamientos, desplazamientos y nuevas configuraciones establecidas por las relaciones económicas, políticas y sociales en tiempos de globalización, con un pathos histórico vivo y una inscripción fuerte de futuro, el Caribe constituye una entidad que sigue eludiendo las definiciones disciplinares y las circunscripciones geográficas, lingüísticas y raciales con las que lo ha querido medir y pesar la racionalidad colonial. ${ }^{1}$ Por eso, una de las mejores formas de pensarlo es en movimiento: diásporas europeas, africanas y asiáticas -como podemos apreciar en el artículo de Luz M. Hincapié- se han concitado en la encrucijada colonial y nuevas diásporas migran desde el Caribe Poscolonial, dando lugar a inéditas convivencias e hibridaciones que rebasan las cartografías originales e inauguran nuevas prácticas discursivas poscoloniales.

William Luis, por su parte, reflexiona alrededor de la producción literaria afrolatina de origen hispano en los Estados Unidos, resultado de sucesivas oleadas poblacionales desde el Caribe hacia Norteamérica, especialmente intensa en el siglo XX. En esta red de narrativas transnacionales se puede leer el conflicto no resuelto entre distintas filiaciones del sujeto migrante: identidad cultural versus identidad nacional, lengua nativa versus lengua de adopción, patria de origen versus sueño americano, entre otras.

El Caribe continental participa sin duda del metarchipiélago caribeño: la inclusión de los escritores del Caribe de Norte, Centro y Suramérica en el campo de los Estudios Caribeños ha establecido un fructífero contrapunto con la producción antillana, particularmente interesante dada su doble pertenencia: por un lado al campo literario nacional de su país y por otro al campo literario caribeño. En el caso colombiano, por ejemplo, el subcampo literario del Caribe ha sido agente de modernización muy prolífico, desde la aparición del Grupo de Barranquilla, la producción del Nobel colombiano, hasta la aparición de voces femeninas, como Marvel Moreno y Fanny Buitrago. "La efervescencia intelectual del Caribe colombiano desde los años 20 es considerada hoy [...] el caldo de cultivo de la modernización de la literatura colombiana", nos recuerda Nadia Celis en su artículo sobre la escritora barranquillera. Precisamente, Buitrago logra

Ver la actualización del debate en: L. Suarez Salazar y G. Amézquita, comps., El Gran Caribe en el Siglo XXI: crisis y respuestas. Buenos Aires: CLACSO, 2013. 
en la ficción novelesca de Los pañamanes (1979) lo que tantos años de historia no han podido lograr en el mundo real: un acercamiento desde el continente a la cultura afroanglo-caribe de San Andrés Islas y Providencia -territorio colombiano de ultramar-, con un diálogo integrador de los relatos fundacionales isleños, explica Ligia Aldana, en un intento de superación de las distancias culturales, políticas y geográficas. Por otra parte, la costa colombiana también vehiculó factores de renovación artística a través de la importación y aclimatamiento de las industrias culturales y el imaginario de los medios masivos del nutrido corredor norte-sur de la segunda postguerra mundial, desde Estados Unidos y México hasta Latinoamérica, como lo muestra la ficción de Ramón Illán Bacca, en palabras de Sarah de Mojica.

La doble pertenencia estratégica-a la vezatlántica y pacífica-así como incoincidencia entre la identidad nacional, definida como mestiza - hispana e indígena- y el territorio nacional, en el que concurren identidades culturales otras resultantes del encuentro colonial, producen en el caso nicaragüense un hiato histórico, político y socio-racial que María Roof ha llamado "las dos Nicaraguas". La inclusión del complejo componente africano de la costa caribe nicaragüense a partir de su inscripción poética ha constituido un proceso creciente y un proyecto contestatario insoslayable, legible en la poesía de Carlos Rigby, David McField, Karl Tinkam, Yolanda Rossman Tejada, Julio Monterrey, Isabel Estrada Colindres, entre otros.

Paralelamente a la literatura escrita, la oralidad circula en el Caribe como un texto cultural innegable. La oralitura de San Basilio de Palenque (Colombia), comunidad afrocriolla patrimonalizada por la UNESCO en el 2005, por ejemplo, ha dado muestras de su increíble productividad, que integra elementos de tradición europea, africana y caribe con un resultado inédito, en una doble vía discursiva -el español y la lengua palenquera- como lo explican Graciela Maglia e Yves Moñino en su análisis sociosemiótico, etnolingüístico y cultural de la literatura oral palenquera. Un rendimiento distinto de la oralidad como instrumento en el contexto del debate de nación de la Revolución Cubana es introducido por Juan Cristóbal Castro, cuyo análisis contrapone por un lado, el recurso homogenizador de la escritura como traducción legítima de la voz nacional cubana en la obra testimonial de Miguel Barnet: Biografía de un cimarrón, y por otro, el "distanciamiento frente [al] núcleo duro de la nacionalidad" de Cabrera Infante en la ficción novelesca de Tres tristes tigres. Allí se recurre al lenguaje coloquial y a la naturalización del choteo cubano en su irreductible opacidad, para dar lugar a la desfiguración de la letra como síntoma de la imposibilidad de una (única) voz nacional.

En el fértil terreno de las refuncionalizaciones caribeñas y a propósito de la obra de Eliseo Altunaga, Silvia Valero nos pone frente a la resemantización del concepto de racialización como valor positivo en la construcción de nuevas subjetividades no reactivas, lejos de las afrorreclamaciones y respuestas defensivas, comprometidas en la afirmación de la identidad negra en el contexto de la sociedad cubana.

$111 \frac{\text { Revista Iberoamericana, Vol. LXXXII, Núms. 255-256, Abril-Septiembre 2016, 285-288 }}{\text { ISSN 2154-4794 (Electrónico) }}$ 
Una nueva economía visual emparentada con los contradictorios procesos de modernización urbana y explotación ambiental deja al descubierto mecanismos de marginación social, discriminación racial e ilícito en los antiguos arrabales de San Juan de Puerto Rico en La casa de la laguna de Rosario Ferré. En efecto, como señala Áurea María Sotomayor, la conexión entre los espacios físicos y su dimensión simbólica, los imaginarios de "lo bajo" y de "lo alto" como polos de coloración afectiva contrapuesta, asociados a "la casa" como microexpresión de una pirámide social que perpetúa los privilegios coloniales, potencian la carga poética de esta apuesta novelesca que termina con un incendio purificador que redime toda injusticia.

Porúltimo, Ludmila Ferrari hace una novedosa lectura visual de la patrimonialización de San Basilio de Palenque, en un artículo que estudia la conformación de sus representaciones identitarias organizadas alrededor de tres ejes fundamentales: "el primer pueblo libre de América", "África en América” y "Obra Maestra del Patrimonio Inmaterial de la Humanidad" (UNESCO).

De este modo, hemos intentado dar protagonismo a textualidades y líneas críticas menos difundidas en el campo que, sin duda, representan una toma de posición significativa y han ido creando un horizonte de expectativas durante los últimos años, como bien lo comprueban tanto la formación de nuevas redes de investigación y las convocatorias de los recientes congresos y publicaciones periódicas en el área. Por otra parte, con la finalidad de difundir nuevos materiales entre los lectores hispanohablantes, hemos traducido del inglés y el francés textos, conferencias y entrevistas que iluminan la genealogía de nuevas prácticas discursivas en el Caribe, a saber: "Sobre la lengua y la creatividad literaria de Aimé Cesaire", de Jean Bernabé; "Creolidad, diversalidad y mundialización", de Raphaël Confiant; "El legado de Eric Williams", de George Lamming; "El Caribe: ¿Cultura o Mimetismo?”, de Derek Walcott; "Del Atlántico negro a la melancolía postcolonial", de Paul Gilroy, "La puesta en relación”, de Patrick Chamoiseau y "Representaciones de la sexualidad femenina en la ficción de Chamoiseau y Confiant: La Chabine y Man Chine”, de Janeth Casas.

Complementan el repertorio de este número las reseñas críticas de John Lipsky, María Eugenia Bancescu y Francisco Aiello, cuyo balance sobre novedades editoriales y avances de investigación en el campo abren la puerta a futuros debates. 